\title{
Georges Molinié, De la beauté
}

\section{Andrea Schellino}

\section{(2) OpenEdition}

\section{Journals}

\section{Edizione digitale}

URL: https://journals.openedition.org/studifrancesi/3268

DOI: $10.4000 /$ studifrancesi.3268

ISSN: 2421-5856

\section{Editore}

Rosenberg \& Sellier

\section{Edizione cartacea}

Data di pubblicazione: 1 juillet 2013

Paginazione: 506-507

ISSN: 0039-2944

\section{Notizia bibliografica digitale}

Andrea Schellino, «Georges Molinié, De la beauté», Studi Francesi [Online], 170 (LVII | II) | 2013, online dal 30 novembre 2015, consultato il 02 février 2023. URL: http://journals.openedition.org/studifrancesi/ 3268 ; DOI: https://doi.org/10.4000/studifrancesi.3268

Questo documento è stato generato automaticamente il 2 février 2023.

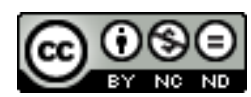

Creative Commons - Attribuzione - Non commerciale - Non opere derivate 4.0 Internazionale - CC BY NC-ND 4.0

https://creativecommons.org/licenses/by-nc-nd/4.0/ 


\title{
Georges Molinié, De la beauté
}

\author{
Andrea Schellino
}

\section{NOTIZIA}

GEORGES MOLINIÉ, De la beauté, Paris, Hermann, coll. «Le Bel Aujourd'hui», 2012, pp. 292.

1 È ancora possibile parlare oggi del bello, e riconoscere nel linguaggio che lo affronta un'orientazione etica? In quale orizzonte s'inscrive la sensazione del bello, nell'ottica di una teoria generale della significazione? E ancora: in quale modo, una volta riconosciuto che ogni linguaggio può funzionare nel regime dell'arte, ciò che ci circonda è «artistisable» (e dunque «littérarisable») e si possono porre le condizioni di un autentico pensiero somatico? Con queste e altre questioni fa i conti Georges MoLINIÉ nel presente volume, proseguendo la sua costruzione di un sistema socio-semiotico, che «repose sur une gerbe d'éléments herméneutiques dont la ligne de fuite suit une ligne de faîte interprétative qu'il finit pour devenir urgent de clarifier, du point de vue d'une esthétique générale de la signification» (p. 10). Un invito a percorrere questa linea interpretativa è data all'A. dalla felice formula di Annie Ernaux, per cui la sensazione della bellezza si nasconde «dans le creux où fusionnent mort, écriture, sexe». In questo luogo si trovano legati ed esposti «l'absolu et la calamité définitoires de l'humain comme l'humain: la mort; l'absolu et la limite illimitée de la désirabilité et de la jouissance; le sexe; l'absolu et l'indépassable de la sur-expérience: l'art comme suprasémiose verbale: l'écriture» (p. 13). La concezione moderna della bellezza giace su due linee di tensione, che non devono per Molinié essere trascurate, sebbene paiano minare la sua possibilità. Da un lato vi è l'accettazione della poetica baudelairiana della charogne, del brutto, che fonda la modernità estetica; dall'altro il ruolo emblematico della Seconda guerra mondiale e di Auschwitz, con la programmazione industriale del genocidio, dell'annientamento, e il progressivo avvento della razionalità capitalistica. Assumere queste due linee di forza non significa per l'A. piegarsi alle aporie contemporanee e alla tanto paventata morte dell'arte; al contrario, esse permettono di riflettere nuovamente sulla significazione e sulla semiotizzazione dei comportamenti sociali e delle prassi artistiche contemporanei, al fine di rifondare «retoricamente» la 
questione del rapporto tra la costellazione linguistica e l'empirico, per ciò che riguarda la bellezza.

2 Nel porre i propri pilastri teorici, Molinié si situa in una prospettiva paradossale, che lo discosta dalla doxa estetica occidentale. "Le test empirique phénoménal le plus dirimant de l'artistisation», scrive l'A., «c'est la sensation de jouissance» (p. 15). Questo godimento integra risentimento intellettuale e reazione morale all'interno di una sensazione che esalta «la saisie laborieuse et commune de l'univers socio-mondain et en fait sentir existentiellement le vécu» (p. 16). Il modello in cui s'identifica questa sensazione è il godimento sessuale. Molinié si premura d'altronde di precisare che questa sessualizzazione del godimento estetico non è figurale, ma reale. L'oggetto del desiderio e del piacere estetico è la scoperta di un'intimità estranea, dell'intimità dell'altro. In quest'ottica, tutte le determinazioni proprie del godimento sessuale intervengono per Molinié nella sensazione di godimento estetico. Così, «l'idée de la double pénétration, pénétration pénétrée-pénétrante, impose aussi la pensée du modèle sexuel comme simulacre seulement (et totalement)» (p. 19). La figura della partecipazione a ciò che è più intimo, il sesso, rappresenta la condivisione dell'opera $\mathrm{e}$ della vocazione artistiche. L'A. analizza i momenti principali di questa sessualizzazione del linguaggio e della significazione estetici (la nudità come chiamata e visione, la corporeità, l'udito e così via). Ciò che si costruisce, nonostante i registri siano eterogenei, è proprio il campo semantico della bellezza: per Molinié «l'affinité de la beauté et du sexuel paraît anthropologiquement former une structure profonde, la plus puissamment explicative dans ce moment de civilisation, à vue non transcendantale, non idéaliste» (p. 109).

3 Il secondo capitolo del volume (La beauté - la vie), piuttosto che soffermarsi sulla plausibilità teorica della tesi centrale del libro, tenta di chiarirne alcuni aspetti da un punto di vista ampiamente culturale. Il modello maggiore di questo paradigma antiidealistico è per Molinié Wilhelm August von Schlegel, che sottolinea a più riprese il radicamento pulsionale e patetico del sentimento del bello (e, negativamente, del sublime). L'asse della teorizzazione di Molinié si fa dunque più esplicitamente orizzontale, e accoglie come ultimo residuale l'umano, il corpo, «en deçà de quoi il n'y a vraiment rien, le rien, le néant, plus rien, ce qui n'a aucun nom dans aucune langue» (p. 140). Di conseguenza, non è sbagliato riconoscere una ricaduta etica di questi principi, giacché è messo in questione l'orizzonte della felicità. Prendendo le mosse da Aristotele, ridefinendone alcuni presupposti teoretici, Molinié propone di ripensare la felicità dell'arte, che è possibile considerare un sostituto del divino: «ce bonheur, si sensuellement manifesté dans l'espace de l'éclat-beauté foudroyant le décor, se matérialise existentiellement, extatiquement, dans l'expérience aussi fulgurante et métamorphique que fugace et aveauglante de l'art» (pp. 190-191). Un altro mondo si apre, una sensazione di sovra-esistenza si impone: in questo processo, una nuova significazione s'incarna e si illumina.

4 Nel terzo capitolo (Du style et de la beauté de la langue), l'A. si concentra infine sul linguaggio verbale, generalizzando le riflessioni precedenti. In questo ambito, la teoria stilistica consente di far emergere la bellezza nella lingua. Questa bellezza, così facile da percepire e difficile da descrivere, intrattiene una «affinité de nature [...] avec l'effet de phagocytation, de matérialisation, de sensibilisation de la substance du contenu, inhérent à la réception d'art» (pp. 264-265). In ultima analisi, l'A. suggerisce la forte problematica morale che resiste alla delucidazione storico-critica, e che può essere 
affrontata grazie alla dinamica sessuale: «la liberté et l'irrépressibilité de la tension sexuelle, comme mesure absolue et de tout respect, et de toute signification, et de toute valeur, pour comprendre et pour poser l'humain à fleur de peau» (p. 289); con essa, Molinié difende la speranza e la forza della bellezza, che «s'illustre et s'épuise dans son incarnation». 